\title{
Study on Bonding Performance Between Overlay Layers of Polymer Modified Asphalt Mixture
}

\author{
Zhou Junyu, Zhu Jipeng \\ College of Science, Nanjing University of Science and Technology, Nanjing, China
}

\section{Email address:}

978938390@qq.com (Zhou Junyu)

\section{To cite this article:}

Zhou Junyu, Zhu Jipeng. Study on Bonding Performance Between Overlay Layers of Polymer Modified Asphalt Mixture. Science Discovery. Vol. 8, No. 5, 2020, pp. 79-82. doi: 10.11648/j.sd.20200805.11

Received: July 28 2020; Accepted: September 8, 2020; Published: September 23, 2020

\begin{abstract}
The asphalt mixture thin overlay is usually paved on the basis of the original pavement sprayed with modified asphalt tack coat oil, and the paving thickness is generally controlled within $2-3 \mathrm{~cm}$. The thin overlay has the advantages of high strength, good durability, good skid resistance, fast construction speed, high efficiency and short open traffic time. It can effectively solve the problems of slight cracks, skid resistance, shallow rutting, water seepage and aging of pavement. Because the paving thickness of the thin overlay is only $2-3 \mathrm{~cm}$, it is difficult to guarantee the bonding force between the overlay and the original pavement layer, which is easy to appear the phenomenon of shear slip between the overlay and the original pavement layer under the load of vehicles, so the interlayer bonding between the overlay and the underlying layer is particularly critical in practical application. This study uses polymer modified asphalt provided by Nanjing limiqing New Material Technology Co., Ltd. in this paper, the bond performance between asphalt concrete and original pavement is tested by pull-out test to verify the bonding performance of the interface, which lays a foundation for the application of thin-layer overlay of asphalt mixture.
\end{abstract}

Keywords: Modified Asphalt, Thin Overlay, Drawing Strength, Bonding Strength, Performance

\section{聚合物改性沥青混合料罩面层间粘结性能研究}

\section{周君宇, 朱吉鹏}

南京理工大学理学院, 南京, 中国

邮箱:

978938390@qq.com（周君宇）

摘要: 沥青混合料罩面通常采用断级配沥青混合料摊铺在洒布改性沥青粘层油的原路面基础上, 推铺厚度一般控制在 2 3 $\mathrm{cm}$ 。罩面强度高、耐久性好、抗滑性能好、施工速度快效率高、开放交通时间短等优点。可以有效解决路面轻微 裂缝, 抗滑性能降低浅车辙, 路面渗水老化等病害。由于罩面摊铺厚度仅为 $2 \sim 3$ 厘米, 层间粘结力很难保障, 罩面层 与原路面层间收到车辆的荷载推移作用，容易出现层间剪切滑移现象，所以在实际应用中罩面层与之下承层的层间粘 结就尤为关键。本次研究使用南京励米青新材料科技有限公司提供的聚合物改性沥青, 本文通过采用拉拔试验对沥青 混凝土与原路面间的粘结性能进行测试，验证该界面的粘结性能，为沥青混合料罩面应用的推广打下基础。

关键词：改性沥青，罩面，拉拔强度，粘结强度，性能 


\section{1. 引言}

在响应国家可持续发展的战略背景下, 在保证路用性 能的前提下减薄沥青混凝土的摊铺厚度是非常有必要的 研究。美国的Novachip是世界上先进的沥青混合料商品, 我国也是在 2003 年引进Novachip专用设备铺筑了实验路 段, 并投入正式应用。国内外专家对罩面做了大量研究, 进行了试验路的铺筑并取得了良好的效果。长安大学于静 涛以层间抗剪强度作为评价指标, 通过室内对比试验研究 了不同层间界面结构类型,防水材料种类及用量对层间稳 定性的影响规律, 研究了桥面板与沥青面层接触条件对沥 青铺装路用性能的影响规律 [1]。《中外公路》时林军选用 不同的粘结层材料及不同的材料用量分别成型复合试件, 在不同的温度下进行抗剪和拉拔试验。通过试验结果分析, 推荐一种效果较好的粘结层材料及其合适的用量[2]。

罩面粘结层材料的作用, 是使上沥青面层与下承层粘 结成一个整体, 在车辆的坚向压力和行驶过程中水平推移 力作用下, 能够抵抗上下层间的各种应力, 保证层与层之 间不滑移，使路面整体具有足够的承载力和优良的路面性
能。罩面的粘结层材料通常采用沥青粘层油, 极重、特重 交通和重交通公路路面的粘层和改建工程加铺层与原路 面之间的粘层, 宜采用改性沥青或改性乳化沥青。

\section{2. 沥青胶结料}

本研究中主要采用拉拔试验对沥青混凝土与沥青混 凝土粘结性能进行测试, 验证该界面的粘结性能[3]。考虑 到聚合物改性沥青材料作为防水粘结层材料所粘结对象 的不同, 此处拉拔试验主要测试聚合物改性沥青材料作为 填缝材料或粘结材料时与沥青混合料的粘结强度 [4], 分别 评价其粘结性能。

常温型聚合物改性沥青由组分 $E$ 、组分F共两个组分组 成, 该聚合物改性沥青由南京励米青新材料科技有限公司 提供。

组分 $\mathrm{E}$ 是一种由聚合物树脂及增韧剂、增容剂、活性 稀释剂组成的匀质合成物, 依照《公路沥青路面施工技术 规范》（JTG F40-2004）的要求对其进行了试验检测, 实 验结果如表1所示。

表1 常温型聚合物改性沥青组分E技术指标。

\begin{tabular}{llll}
\hline 物理性能 & 规定值 & 实测值 & 试验方法 \\
\hline 粘度 $\left(30^{\circ} \mathrm{C}\right) / \mathrm{mPa} \cdot \mathrm{s}$ & $500 \sim 2000$ & 1485 & ASTM D 2041 \\
比重 $\left(25^{\circ} \mathrm{C}\right)$ & $0.88 \sim 1.05$ & 0.92 & ASTM D 1475 \\
外观 & 透明琥珀色至淡黄色液体 & 透明琥珀色至淡黄色液体 & 肉眼观测 \\
\hline
\end{tabular}

组分 $\mathrm{F}$ 是一种由石油沥青、固化促进剂和固化剂组成的匀质合成物。其技术要求与实测试验结果如表2所示。

表2 常温型聚合物改性沥青组分F技术指标。

\begin{tabular}{llll}
\hline 物理性能 & 规定值 & 实测值 & 试验方法 \\
\hline 粘度 $\left(30^{\circ} \mathrm{C}\right) / \mathrm{mPa} \cdot \mathrm{s}$ & $1000 \sim 3800$ & 2348 & ASTM D 2041 \\
比重 $\left(25^{\circ} \mathrm{C}\right)$ & $0.98 \sim 1.25$ & 1.09 & ASTM D 1475 \\
外观 & 黑色液体 & 黑色液体 & 肉眼观测 \\
\hline
\end{tabular}

组分 $\mathrm{E}$ 与组分 $\mathrm{F}$ 按照一定比例在 $10^{\circ} \mathrm{C} \sim 50^{\circ} \mathrm{C}$ 条件下按 600RPM均匀搅拌2min之后得到常温型聚合物改性沥青胶 结料。

\section{3. 沥青胶结料拉拔强度测试}

\section{1. 拉拔试验}

为了测试粘结料与沥青混凝土之间的粘结强度, 试件 考虑采用“沥青混合料--聚合物改性励青粘结料--沥青混 合料”的方式。首先制作试验所需沥青混凝土板, 成型时, 首先下垫 $3 \mathrm{~cm}$ 厚木板, 然后按照成型车辙板试件的方法制 作 $2 \mathrm{~cm}$ 厚的沥青混凝土板 4 块, 待此板充分固化后在其表面 涂抹沥青粘结料, 结合以往的实验经验按照 $0.30 \mathrm{~L} / \mathrm{m}^{2}$ 、 $0.45 \mathrm{~L} / \mathrm{m}^{2} 、 0.65 \mathrm{~L} / \mathrm{m}^{2} 、 0.80 \mathrm{~L} / \mathrm{m}^{2}$ 的四个用量梯度分别涂抹[5]。 待粘结层稍固化后摊铺剩下 $3 \mathrm{~cm}$ 板厚所需用沥青混凝土, 随后仍旧利用轮碾法成型。注意在涂膜时应在沥青混凝土 板四周做好围挡, 防止沥青粘结料随板边缘流淌 [6]。

待整个试验用沥青混凝土板达到强度后, 用钻芯机采 用直径为 $50 \mathrm{~mm}$ 的钻筒在板上钻取芯样, 钻芯时不钻通。

待芯样全部钻取结束后, 清理试件表面, 用聚合物改性树 脂 $\mathrm{AB}$ 胶将直径为 $50 \mathrm{~mm}$ 的圆形钢接头固定在芯样上, 待 $\mathrm{AB}$ 胶完全固化后则可以进行开始拉拔试验[7]。

试验时将拉拔试件上置钢板, 钢板中央有一圆形洞口 可以容许拉接头通过[8], 通过调整垫块位置将钢板尽量调 水平, 随后将拉拔试验仪放置于钢板上。

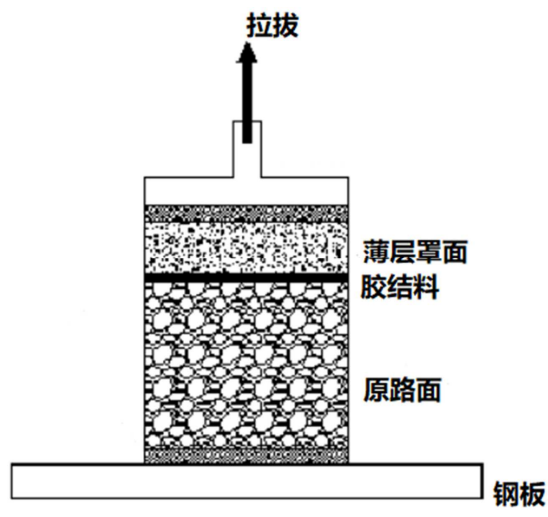

图1 拉拔试验原理。 
将试验仪连接电脑及加载设备, 将连接杆分别旋进接 头及拉拔试验仪, 旋紧后检查是否与钢板垂直 [9]。随后启 动仪器, 以 $10 \mathrm{~mm} / \mathrm{min}$ 的加载速度施力于拉杆, 直到芯样 被拉起破坏。试验设备将自主记录破坏时的最大荷载及荷 载—位移关系曲线[10]。

\section{2. 拉拔试验结果分析}

在 $23^{\circ} \mathrm{C}$ 及 $60^{\circ} \mathrm{C}$ 条件下, 测试完成 “聚合物改性沥青混 凝土+聚合物改性沥青粘结材料+钢板”全部芯样的拉拔强 度, 得到实验数据汇总如表 3 。

表3 聚合物改性沥青粘结料的拉拔试验结果数据汇总。

\begin{tabular}{|c|c|c|c|c|}
\hline 试验温度 $\left({ }^{\circ} \mathbf{C}\right)$ & 试件编号 & 结交料 $\left(\mathrm{L} / \mathrm{m}^{2}\right)$ & 抗拉强度(MPa) & 破坏面 \\
\hline \multirow{4}{*}{23} & \multirow{4}{*}{ A1 } & 0.30 & $3 . .09$ & 沥青混合料间粘结层 \\
\hline & & 0.45 & 3.56 & 沥青混合料间粘结层 \\
\hline & & 0.65 & 4.10 & 沥青混合料间粘结层 \\
\hline & & 0.80 & 3.44 & 拉头和胶黏剂间 \\
\hline \multirow{4}{*}{60} & \multirow{4}{*}{ B1 } & 0.30 & 2.13 & 沥青混合料间粘结层 \\
\hline & & 0.45 & 2.87 & 沥青混合料间粘结层 \\
\hline & & 0.65 & 3.02 & 拉头和胶黏剂间 \\
\hline & & 0.80 & 2.67 & 沥青混合料间粘结层 \\
\hline
\end{tabular}

从表 3 可知, 总体上随着环境温度的升高, 粘结料的 粘结强度呈明显的下降趋势。这也符合沥青本身随着温度 升高而逐渐软化的特性 $[11]$ 。可以看到, 在 $60^{\circ} \mathrm{C}$ 时, 有一 个芯样的破坏是发生在沥青混合料间而非粘结层，也证明 聚合物改性沥青混合料本身抗拉强度也是随着温度的升 高而降低的[12]。

对于沥青混合料层间粘结的试件, 可以发现 $23^{\circ} \mathrm{C}$ 试验 时, 抗拉强度均大于 $3 \mathrm{MPa}$, 且此时破坏为接头破坏, 理 论上粘结层的粘结强度应大于测得的粘结强度数据 [13]。 在 $60^{\circ} \mathrm{C}$ 材料粘结强度大幅下降的情况下, 只对比粘结层破 坏的试件, 则两种混合比的试件粘结强度差异并不大, 且 存在试件发生了在沥青混合料中的断裂情况[14]。可以基 本认定, 在高温条件下粘结料普遍粘结性能较好, 混合比 对其影响并不大。

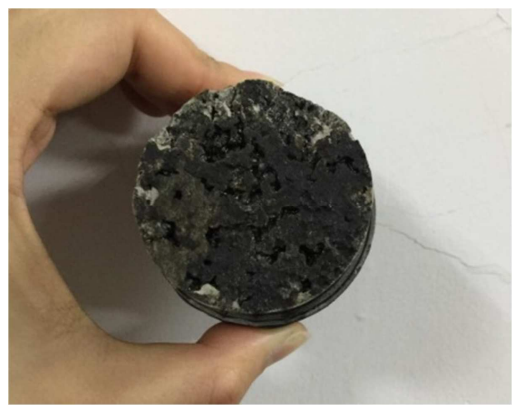

图2 $60^{\circ} \mathrm{C}$ 时粘结层破坏断面。
同时，通过观察高温下的粘结层发生破坏的试件（图 2) 可以发现, 虽然温度变高粘结层会略有些软化, 但其 整体仍然处于固态，这表明该类材料可以承受的住 $60^{\circ} \mathrm{C}$ 高温对于其粘结性的影响。

总的来说, 该类材料粘结性能优异且在温度较高时能 保证不发生流动, 可以保证修补作业的施工质量。该聚合 物改性沥青粘结料在较长时间内不发生高温破坏 [15]。

\section{4. 沥青胶结料抗剪强度测试}

\section{1. 抗剪试验}

为研究常温型聚合物改性沥青的粘结能力, 采用斜剪 试验来评价该改性沥青的抗剪强度 [16]。试验设计如下： 参考国内外现有研究成果, 取两块表面平整的混凝土块, 大小为 $50 \mathrm{~mm} \times 50 \mathrm{~mm} \times 35 \mathrm{~mm}$ (长 $\times$ 宽 $\times$ 厚)，在混凝土块的 的表面涂上 $0.65 \mathrm{~L} / \mathrm{m}^{2}$ 聚合物改性沥青结合料, 然后将混凝 土块粘结在一起。将试件放在 $40^{\circ} \mathrm{C}$ 的烘箱中保温 24 小时 [17]。随后, 在 $20 \pm 1^{\circ} \mathrm{C}$ 条件下, 使用 SANS 万能试验机对 试件进行抗剪试验。

\section{2. 抗剪试验结果分析}

将 $40^{\circ} \mathrm{C}$ 保温 24 小时后的试件取出, 在 $20 \pm 1{ }^{\circ} \mathrm{C}$ 条件下测 试试件的抗剪强度, 具体试验数据详见表 4 。

表4 修复界面抗剪试验。

\begin{tabular}{llll}
\hline 样品编号 & 最大剪力/KN & 抗剪强度/MPa & 平均值/MPa \\
\hline 常温型聚合物改性沥青-1 & 10.6 & 4.32 & \\
常温型聚合物改性沥青-2 & 10.3 & 4.28 & 4.31 \\
常温型聚合物改性沥青-3 & 11.1 & 4.35 & \\
\hline
\end{tabular}

由表 4 可知, 常温型聚合物改性沥青胶结料的平均最 大剪力为 $10.6 \mathrm{KN}$, 平均抗剪强度 $4.31 \mathrm{MPa}$, 证明其具有优 异的抗剪强度。该强度值与美国温拌聚合物沥青、日本热 拌聚合物沥青粘结料性能相当, 说明本作品的产品具有很
好的粘结能力[18]错误!未找到引用源。。部分试验的破坏 发生在混凝土块, 说明该型常温型聚合物改性沥青的粘结 界面强度已超过混凝土的抗剪强度, 显示出该材料具有很 好的粘结性能。 


\section{5. 总结}

根据上述关于常温型聚合物改性沥青的拉拔实验, 确 定了罩面与原路面之间胶结料适宜用量为 $0.65 \mathrm{~L} / \mathrm{m}^{2}, 23^{\circ} \mathrm{C}$ 时时的拉拔强度最高能达到 $4.10 \mathrm{MPa}, 60^{\circ} \mathrm{C}$ 时的拉拔强度 最高能达到 $3.02 \mathrm{MPa}$, 均满足相关规定的 $1.5 \mathrm{MPa}$ 的技术要 求。随着环境温度上升胶结料的确会存在些许软化, 但是 整体仍然保持固态状态, 表明该类沥青胶结料可以承受 $60^{\circ} \mathrm{C}$ 高温对于其粘结性的影响, 证明该沥青胶结料是可以 保证夏季时间罩面的安全使用功能。

利用拉拔试验得出的最佳胶结料用量 $0.65 \mathrm{~L} / \mathrm{m}^{2}$, 进一 步通过抗剪实验证明常温型聚合物改性沥青具有优异的 抗剪强度, 保障罩面与原路面之间不出现层间剪切滑移现 象。

\section{参考文献}

[1] 于静涛. 励青铺装与桥面板层间粘结改善技术研究[D]. 长 安大学,2006。

[2] 时林军. 超薄面层层间粘结技术研究 [J]. 中外公路,2011。

[3] 高金岐,罗晓辉,徐世法,等.沥青粘结层抗剪强度试验分析 [J]. 北京建筑工程学院学报,2003(01):69-74。

[4] 常艳婷,陈忠达,张震, 等. Study of Epoxy Emulsified Asphalt Binder Layer Performance of Asphalt Bridge Deck Pavement\%[J]. 材料导报,2015,029(018):103-107。

[5] 左秋英,查旭东,陈炜,等.环氧改性沥青粘结层试验研究 [J]. 公路与汽运,2007,000(001):94-96。
[6]陈先华,黄卫,游庆仲,等.环氧沥青粘结层施工均匀性的影响 因素与改善措施 [J]. 公路交通科技: 应用技术 版,2008,000(001):P.148-149,158。

[7] 支永光, 程刚,王利杰.钢桥面铺装环氧沥青粘结层施工 [J]. 浙江交通职业技术学院学报,2004(04):9-12+8。

[8] 侯航舰.沥青粘结层抗剪强度试验探析[J]. 郑州大学学报 (工学版),2006,027(003):38-41,58。

[9] 江虹,王雷. 桥面铺装中高粘沥青粘结层施工技术[C]// 2016 年建筑科技与经济学术交流会. 2016。

[10] 怀丽,刘洋.环氧沥青粘结层酒布施工控制[C]// 公路交通与 建设论坛(2009). 2010。

[11] 汪日灯. 沥青混合料桥面铺装防水粘结层研究 [D]. 长安大 学, 2008。

[12] 赵胜. 基于层次分析法的水泥/沥青混凝土复合路面层间粘 结材料的研究 [J]. 科学技术创新,2018,000(001):P.139-140。

[13] 黄晖.湛江海湾大桥钢桥面环氧沥青粘结层酒布施工工艺 [J]. 公路交通技术,2008,000(003):94-96。

[14] 高畅.钢桥面铺装环氧沥青粘结层施工质量控制 [J]. 广东交 通职业技术学院学报,2007(03):43-44+47。

[15] 管相礼. 钢箱梁桥面铺装中的环氧沥青粘结层酒布的工艺 改进 $[\mathrm{J}]$. 投资与创业,2012,000(004):66,69。

[16] 刘朝晖,郑健龙. $\mathrm{CRC}+\mathrm{AC}$ 复合式沥青路面层间界面粘结层 抗剪强度试验研究 [J]. 中外公路,2007(04):50-53。

[17] 许涛,黄晓明.高剂量SBS改性沥青桥面防水粘结层施工[J]. 施工技术,2006(10):32-33+74。

[18] 苏新国,颜赫,鲁圣弟, 等.沥青路面层间粘结效果影响因素 [J]. 长安大学学报(自然科学版),2013,033(003):21-26,68。 